ORIGINAL ARTICLE

\title{
Heliox in the treatment of chronic obstructive pulmonary disease
}

\section{R Andrews, M Lynch}

Emerg Med J 2004;21:670-675. doi: 10.1136/emj.2003.011486

See end of article for authors' affiliations

.....................

Correspondence to: Dr R Andrews, 12 Marcilly Road, Wandsworth London SW18 2HS, UK; bob.doc@btinternet.com

Accepted for publication 4 December 2003
Objective: To determine if breathing helium oxygen mixtures in addition to conventional therapy in nonintubated adult chronic obstructive airways disease (COPD) patients reduces the arterial partial pressure of carbon dioxide $\left(\mathrm{PaCO}_{2}\right)$ more than conventional treatment alone, and confers an advantage in terms of the odds of intubation in the acute setting.

Design: Meta-analysis.

Setting: Diverse settings.

Participants: Adult patients with a diagnosis of either stable severe or acute COPD.

Main outcome measures: Decrease in partial pressure of arterial $\mathrm{PaCO}_{2}$ and intubation rates.

Results: Combination of the results from trials measuring change in $\mathrm{PaCO}_{2}$ in $\mathrm{COPD}$ subjects receiving conventional therapy but breathing helium-oxygen estimated a reduction of $0.78 \mathrm{KPa}(1.44-0.13)$ beyond that produced by conventional therapy with air-oxygen breathing $(n=234)$. Using quantitative and qualitative measures of validity it was found that most trials were unsatisfactory. Chief concerns were poor concealment of allocation and lack of blinding. Analysis excluding all papers with low methodological quality (Jadad $<2$ ) estimated the reduction in $\mathrm{PaCO}_{2}$ conferred by use of Heliox breathing to be $0.22 \mathrm{KPa}(+0.57$ to -0.14$)$. A non-significant reduction $(p=0.2)$. When combined, the results from trials measuring the intubation rates of patients treated conventionally or with Heliox $(n=121)$ the odds ratio of intubation was $0.096(0.03-0.27)$.

Conclusion: Definitive evidence of a beneficial role of Heliox in treatment of severe COPD is lacking and therefore its wide scale use cannot be recommended based on this analysis. However, as a beneficial effect of Heliox breathing was reported in all trials, further investigation with a well conducted randomised controlled trial is warranted.
$\mathrm{T}$ reatment in acute chronic obstructive pulmonary disease (COPD) is directed at improving gas exchange and decreasing the work of breathing. In the most severe exacerbations of COPD this is achieved by intubation and mechanical ventilation. However this approach is associated with several problems including ventilator associated pneumonia, ventilator induced lung injury, and deconditioning of respiratory muscles leading to ventilator dependence. Recently strategies to avoid intubation and mechanical ventilation have been examined. Much success has been seen with non-invasive ventilation (NIV) in selected COPD patients who would have otherwise been intubated and mechanically ventilated. Another strategy in severe COPD entails changing the physical properties of the gas the patient inspires. Substituting helium for nitrogen results in a lighter carrier gas for oxygen, Heliox, this can be used in conjunction with all conventional treatments including NIV.

The behaviour of gas flows in the lungs determines the pressure required to drive the gas. Gas movement may be: laminar, where the molecules flow in parallel lines; turbulent, where the molecules flow in a haphazard fashion or transitional, where there is a combination of both laminar and turbulent flow. Laminar flow is far more energy efficient and requires lower pressures to achieve a given flow rate. Gases are more likely to flow in a laminar pattern if they are of low density and high viscosity. Because Heliox has a significantly lower density (and a slightly higher viscosity) than air it is more likely to exhibit laminar flow when travelling through the bronchial tree. Additionally, when there is turbulent or transitional flow gases of lower density require less pressure to drive ventilation. As Heliox has lower density than air it will flow more efficiently in turbulent conditions. Papamoschou, using a fluid mechanical model of the human lung, described a theoretical analysis comparing flow rates of Heliox and air-oxygen mixtures. The author found there was a 50\% improvement in flow rates if nitrogen was substituted with helium. ${ }^{1}$

Several case reports in the literature attest to the benefits of Heliox in severe COPD. ${ }^{2-4}$ In one, an American patient was being treated in an emergency department with maximal conventional treatment (including NIV). Despite this he continued to deteriorate. Within 20 minutes of introduction of Heliox therapy his arterial blood gas parameters had improved and he was objectively and subjectively less breathless. Intubation was avoided and he was discharged within six days. ${ }^{4}$ This case illustrates the potential of the treatment. However in a rigorous systematic review performed by the Cochrane group 5 the reviewers concluded that there was insufficient evidence to support use of Heliox in COPD treatment. Many trials were excluded from this review and it has been criticised as the conclusion was based on just two trials, one of which did not examine continuous Heliox breathing. This review attempts to incorporate all levels of evidence to reduce the likelihood of a type II statistical error in assessing the value of Heliox in COPD management.

\section{CRITERIA FOR INCLUSION Types of studies}

Only controlled studies were considered for inclusion. In the case of parallel groups historical controls were accepted.

Abbreviations: COPD, chronic obstructive pulmonary disease; NIV, non-invasive ventilation 


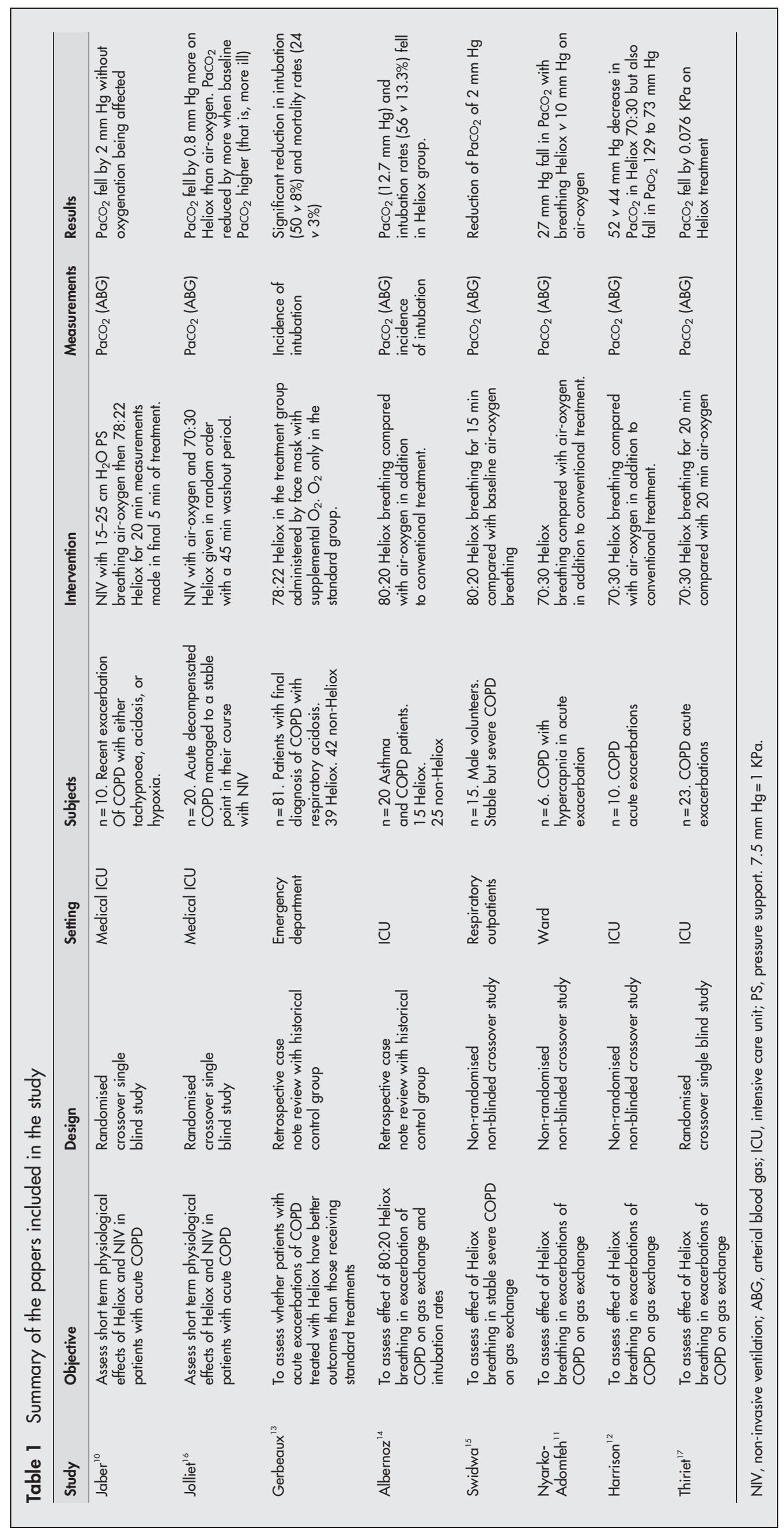


Table 2 Summary of the study appraisal

\begin{tabular}{|c|c|c|c|c|c|c|c|c|}
\hline & Swidwa ${ }^{15}$ & Jaber $^{10}$ & Harrison ${ }^{12}$ & $\begin{array}{l}\text { Nyarko- } \\
\text { Adomfeh" }\end{array}$ & Jolliet $^{16}$ & Gerbeaux $^{13}$ & Albornoz $^{14}$ & Thiriet $^{17}$ \\
\hline \multicolumn{9}{|l|}{ Internal validity } \\
\hline Randomisation & $\begin{array}{l}\text { Non- } \\
\text { randomised }\end{array}$ & $\begin{array}{l}\text { Randomised but } \\
\text { no details of } \\
\text { allocation sequence } \\
\text { generation or } \\
\text { concealment }\end{array}$ & $\begin{array}{l}\text { Non- } \\
\text { randomised }\end{array}$ & $\begin{array}{l}\text { Non- } \\
\text { randomised }\end{array}$ & $\begin{array}{l}\text { Randomised } \\
\text { concealment } \\
\text { achieved } \\
\text { using sealed } \\
\text { envelopes }\end{array}$ & $\begin{array}{l}\text { Non- } \\
\text { randomised. } \\
\text { Subjects } \\
\text { allocated } \\
\text { according to } \\
\text { clinician } \\
\text { preference }\end{array}$ & $\begin{array}{l}\text { Non- } \\
\text { randomised }\end{array}$ & $\begin{array}{l}\text { Randomised } \\
\text { but no details } \\
\text { of } \\
\text { concealment } \\
\text { of allocation }\end{array}$ \\
\hline Blinding & No blinding & $\begin{array}{l}\text { Subjects blinded } \\
\text { but no blinding } \\
\text { of clinicians. } \\
\text { No blinding of } \\
\text { statisticians to } \\
\text { results }\end{array}$ & No blinding & No blinding & $\begin{array}{l}\text { Subjects } \\
\text { blinded but } \\
\text { no blinding } \\
\text { of clinicians. } \\
\text { No blinding } \\
\text { of statisticians } \\
\text { to results }\end{array}$ & $\begin{array}{l}\text { Blinding of } \\
\text { observers to } \\
\text { evolution of } \\
\text { patient but } \\
\text { not Heliox, } \\
\text { blinding of } \\
\text { authors to } \\
\text { use of Heliox, } \\
\text { but not of } \\
\text { evolution }\end{array}$ & No blinding & No blinding \\
\hline Patient attrition & No attrition & $\begin{array}{l}\text { Attrition }<10 \% \text { : } \\
\text { one patient refused } \\
\text { consent. One } \\
\text { patient withdrawn } \\
\text { due to condition. }\end{array}$ & No attrition & $\begin{array}{l}\text { No details } \\
\text { supplied }\end{array}$ & No attrition & No attrition & No attrition & No attrition \\
\hline $\begin{array}{l}\text { Statistical } \\
\text { analysis } \\
\text { External validity }\end{array}$ & No details & Appropriate tests & No details & No details & $\begin{array}{l}\text { Appropriate } \\
\text { test }\end{array}$ & $\begin{array}{l}\text { Appropriate } \\
\text { tests }\end{array}$ & No details & $\begin{array}{l}\text { Appropriate } \\
\text { tests }\end{array}$ \\
\hline $\begin{array}{l}\text { Inclusion/ } \\
\text { exclusion } \\
\text { criteria supplied }\end{array}$ & Yes & Yes & No details & No details & Yes & Yes & Yes & No details \\
\hline $\begin{array}{l}\text { Treatment } \\
\text { regimens } \\
\text { described }\end{array}$ & Yes & Yes & $\begin{array}{l}\text { Yes but no } \\
\text { indication of } \\
\text { duration of } \\
\text { treatment }\end{array}$ & $\begin{array}{l}\text { Yes but no } \\
\text { indication of } \\
\text { duration of } \\
\text { treatment }\end{array}$ & Yes & Yes & $\begin{array}{l}\text { Yes but no } \\
\text { indication of } \\
\text { duration of } \\
\text { treatment }\end{array}$ & Yes \\
\hline $\begin{array}{l}\text { Summary Jadad } \\
\text { quality assessment } \\
\text { scale (0-3) }\end{array}$ & 1 & 2 & 1 & 0 & 3 & 1 & 1 & 2 \\
\hline
\end{tabular}

Randomisation and blinding although desirable were not mandatory.

\section{Participants and settings}

Adults, aged over 18 years, with a clinical diagnosis of COPD or emphysema. The patients were ideally being treated for acute exacerbations however if their condition was stable at the time of study their underlying COPD should be severe according to pulmonary function testing.

Studies involving asthmatic subjects exclusively were excluded. Studies involving both COPD and asthma were included if the proportions of each condition were similar in the intervention and control group. Studies examining mechanically ventilated subjects were excluded.

The ideal setting would be the emergency department; however there were too few studies conducted in this environment to make this feasible as an inclusion criterion. Many diverse settings were included.

\section{Types of intervention}

Self ventilation with Heliox-oxygen mixtures, the oxygen composition of which should not exceed $40 \%$. All cointerventions should be the same between control and treatment groups in the study.

No restrictions on types of co-intervention were applied and trials of Heliox used with NIV and given via facemask without pressure support were included.

Studies using helium-oxygen as a driving gas for nebulised drugs were excluded as this does not examine Heliox breathing as a treatment in its own right.

\section{Types of outcome measures}

Decrease in $\mathrm{PaCO}_{2}$ was chosen as a marker of improved alveolar ventilation.

The clinical outcome of intubation of the patient taken to represent a failure of treatment.

\section{SEARCH STRATEGY AND RESULTS OF SEARCH}

Embase and Medline databases were searched from 1966 to 2002 using the Ovid and Zetoc (Athens) interphase. No restrictions were made on language or publication type.

The search strategy used the following terms

(1) COPD OR COAD OR CAL OR chronic bronchitis OR emphysema

(2) Heliox OR Helium and oxygen

Search 1 and 2 were combined using the Ovid interphase

A further search was also conducted using the search term Heliox. References including the term in any medical context were examined for suitability.

Citations taken from publications retrieved were also examined for suitability if not already located in the database searches.

BOC medical was contacted for additional references.

Tables of contents for key medical journals were examined using the Zetoc notification system over a six month period (September 2002-February 2003).

The database searches revealed 29 publications (17 Embase and 20 Medline). Where possible, studies were excluded by examination of the title or abstract. Nine publications were retrieved from the British Library and a search of the citations in these papers yielded three further studies. By hand searching archives of respiratory journals a further two abstracts of 


\begin{tabular}{|c|c|c|c|c|c|c|c|}
\hline Citation & Effect & Lower & Upper & -4.00 & -2.00 & 0.00 & 2.00 \\
\hline Albomoz 1998 & -3.134 & -4.132 & -2.137 & & $\square$ & & \\
\hline Harrison 1995 & -1.676 & -2.802 & -0.549 & & & & \\
\hline Jaber 2000 & -0.204 & -1.206 & 0.799 & & & & \\
\hline Jaber 2000 & -0.138 & -1.079 & 0.803 & & & & \\
\hline Jolliet 1999 & -0.432 & -1.051 & 0.216 & & & & \\
\hline Nyarko-Adomfeh 1995 & -0.788 & -1.772 & 0.196 & & & 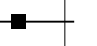 & \\
\hline Swida 1985 & -0.167 & -0.917 & 0.582 & & & & \\
\hline Thiriet 1979 & -0.075 & -0.669 & 0.520 & & & & \\
\hline Combined (8) & -0.782 & -1.438 & -0.125 & & & & \\
\hline
\end{tabular}

interest were retrieved. Exclusion criteria were applied to all papers in the set.

Two papers were not available (although the parent journal was contacted) as they were published as reports from conference proceedings. One paper in Russian was excluded as translation could not be arranged. From the remaining papers five were excluded and an exclusion log was kept (see appendix, available on the journal web site http://www. emjonline.com/supplemental).

Table 1 summarises the papers included.

\section{METHODS}

An assessment of study qualities was made using the criteria laid out in the Chalmers scale, a checklist of best practice in therapy trials. ${ }^{6}$ This qualitative assessment was further supplemented by quantitative scoring based on a scale devised by Jadad. This scale returns one point each for adequate sequence allocation, blinding, and handling of patient attrition if recorded, giving a score of $0-5$ with 5 being the best. Table 2 shows a summary of this appraisal.

Data were extracted from the trial summary statistics and weighting was applied according to the precision of the study.

Because of heterogeneity of design combination was possible in six studies for the outcome measure of reduction in $\mathrm{PaCO}_{2}$. In these studies reductions in partial pressure of arterial carbon dioxide after addition of Heliox was reported. The assumption is made that any improvement in $\mathrm{PaCO}_{2}$ occurs instantly due to improved alveolar ventilation. These results were combined to give a summary statistic reflecting true decrease in $\mathrm{PaCO}_{2}$. The Hedges' adjusted g standardised mean difference method was used to determine the size of the treatment effect in each trial. These were then combined using the DerSimonian and Laird random effects model to give a final summary statistic.

A sensitivity analysis was then performed on methodological grounds, followed by an investigation of the heterogeneity in the study trials.

Two further studies reported the effect of Heliox on intubation rates in COPD exacerbations in the acute setting. Using trial data the odds ratios for intubation with Heliox and conventional treatment were calculated and combined using the Mantel-Haenszel estimate.

All calculations were performed by hand and then checked using Comprehensive Meta Analysis, a commercial medical meta analysis software package.

\section{RESULTS}

Table 2 summarises the methodological properties of each paper.

The internal and external validity of all the studies was examined and significant sources of bias, based on Chalmers scale ${ }^{6}$ were apparent. These were attributable to nonrandomisation and lack of blinding. Using the Jadad scale of validity $^{7}$ it was found that most trials were unsatisfactory, scoring lower than 2. Studies published in abstract form lacked the information required to perform a detailed critical analysis, however in a complete systematic review it is recommended they be included ${ }^{8}$ to avoid exclusion of important data.

The results of examination and manipulation of the data for the outcome of reduction in $\mathrm{PaCO}_{2}$ in Heliox treated and conventionally treated patients $(n=234)$ for the six trials is displayed in a forest plot (fig 1 ).

Combination of data from all trials suggests a reduction of $\mathrm{PaCO}_{2}$ of $0.78 \mathrm{KPa}$ ( 1.44 to 0.13 ) beyond that produced by conventional treatment.

In the study by Jolliet it was further noted that the magnitude of reduction in $\mathrm{PaCO}_{2}$ may be correlated with baseline $\mathrm{PaCO}_{2}$. That is, sicker patients with a higher initial $\mathrm{PaCO}_{2}$ benefited more from the use of Heliox.

Figure 2 shows the result of combination of data from trials measuring intubation rates of patients treated conventionally or with Heliox $(\mathrm{n}=121)$.

The odds ratio of intubation for all patients treated with Heliox during an acute exacerbation of COPD compared with conventionally treated patients was 0.096 (0.03 to 0.27). That is the odds of intubation in a severe exacerbation are reduced by a factor of 10. Converting this to risk ratios, an $82 \%$ reduction in risk of intubation may be conferred by addition of Heliox in patients with exacerbations of COPD.

A sensitivity analysis excluding all papers with low methodological quality $(\mathrm{Jadad}<2$ ) estimated the reduction
Citation
Effect Lower Upper
0.01
$0.1 \quad 1$
10
100 Figure 2 Reduction in odds ratios for intubation.

$\begin{array}{lrrr}\text { Albornoz 1998 } & 0.121 & 0.022 & 0.652 \\ \text { Gerbeaux 2001 } & 0.083 & 0.022 & 0.313 \\ \text { Combined (2) } & \mathbf{0 . 0 9 6} & \mathbf{0 . 0 3 4} & \mathbf{0 . 2 7 2}\end{array}$
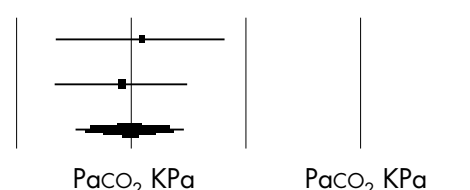
Citation

$\begin{array}{llll}\text { Jaber } 2000 & -0.204 & -1.206 & 0.799 \\ \text { Jaber } 2000 & -0.138 & -1.079 & 0.803 \\ \text { Jolliet } 1999 & -0.432 & -1.081 & 0.216 \\ \text { Thiriet } 1979 & -0.075 & -0.669 & 0.520 \\ \text { Combined (4) } & \mathbf{- 0 . 2 1 7} & \mathbf{- 0 . 5 7 5} & \mathbf{0 . 1 4 0}\end{array}$

Effect Lower Upper $\mathbf{- 4 . 0 0}$

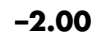

0.00

2.00

4.00

methoduction in $\mathrm{PaCO}_{2}$ most methodologically robust trials. in $\mathrm{PaCO}_{2}$ conferred by use of Heliox breathing to be $0.22 \mathrm{KPa}$ $(+0.57$ to -0.14$)$ (fig 3$)$.

A further analysis removing trials that did not explicitly exclude asthmatic subjects estimated the reduction in $\mathrm{PaCO}_{2}$ to be 0.40 ( 0.76 to 0.05$)$.

Heterogeneity in the trials of reduction in $\mathrm{PaCO}_{2}$ was examined and the $\mathrm{Q}$ statistic (measure of heterogeneity following a $\chi^{2}$ probability distribution) was 37.23 meaning that the studies were highly heterogeneous. Examining the subgroup of the most methodologically robust studies, statistical tests suggested little heterogeneity. For the subgroup of lower quality studies heterogeneity remained suggesting a property of these studies that increased their variability beyond the play of chance. This may be explained by the variety of settings and protocols used in these studies (more robust studies were all ITU based).

One possible source of heterogeneity is the co-intervention of NIV. When reduction in $\mathrm{PaCO}_{2}$ in studies using NIV was compared with those not using NIV, the effect attributable to Heliox was less in the studies using NIV and this difference approached statistical significance $(p=0.16)$. That is, there appeared to be a proportional reduction in benefit of Heliox when used in combination with NIV.

\section{DISCUSSION}

Unfortunately much of the evidence in this review is of low methodological quality. With regard to the end point of reduction in $\mathrm{Pa} \mathrm{CO}_{2}$, once low quality evidence was excluded the estimate of treatment effect became quite modest with confidence intervals crossing the line of no effect $(p=0.2)$. However, one must accept the difficulties associated with studying Heliox making rigorous scientific assessment problematic. Blinding is difficult as investigator and patient can easily detect the change in voice when breathing Heliox and technical details in administration of Heliox prevent blinding of the investigator. Satisfactory randomisation, however, could have been attempted. This was only achieved in three trials (Jaber, Thiriet, and Jolliet) and has the effect of undermining the validity of the analysis. Therefore for future trials proper randomisation is mandatory to add new evidence.

The absence of blinding and randomisation does not totally invalidate trials of treatment but it is estimated that it may exaggerate the treatment effect by up to $40 \% .{ }^{9}$ If the results are adjusted to take this into account there is only an insignificant treatment effect.

Many of the trials used stable patients rather than patients with acute severe COPD in whom benefits may be greater, thus it is possible that the data used for the outcome of reduction in $\mathrm{PaCO}_{2}$ may underestimate the clinical value of Heliox treatment. Also it is highly probable that the way Heliox breathing affects the pathophysiology of COPD is multifactorial and other processes outside the scope of this analysis may contribute to overall improvement in clinical outcome such as reduced dynamic hyperinflation and work of breathing. These are not directly assessed by $\mathrm{PaCO}_{2}$ and may explain why despite a modest reduction in $\mathrm{PaCO}_{2}$ there is a striking effect on odds of intubation.

The estimation of the true odds ratios for intubation in intervention and control groups was also biased because of poor methodology. Most importantly both studies were retrospective case note reviews and used historical control groups, resembling more a cross sectional study than a true trial in that the participants were not assigned to control or intervention groups by methods that are bias averse. These groups could easily have varied in ways other than the intervention under investigation. This is especially true for the Gerbeaux study, where the type of intervention the patient received was determined by the emergency physician treating the patient. The authors admit that only three of seven clinicians in their department favoured the use of Heliox, thus the variability of skills of the clinician treating the patient in the trial becomes highly significant, and as there was no attempt to standardise this by protocol, the variability pollutes the overall study results.

An investigation into heterogeneity showed differences between Heliox delivered by NIV and by face mask, which although not significant might suggest that only modest additional benefits in alveolar ventilation are achieved by adding Heliox to the NIV regimen.

The cost of Heliox treatment is about $£ 500$ per day depending on the oxygen concentration the patient requires. If this is compared with the cost of mechanical ventilation in the ITU (about $£ 1500$ per day) there is an overall cost saving for Heliox treatment. However, comparing Heliox and NIV in a high dependency setting the costs are probably comparable.

Two of the trials (Thiriet and Harrison) reported a decrease in partial pressure of oxygen when Heliox treatment was started but this effect was not seen in any of the other trials. No other adverse effects are reported.

In conclusion, definitive evidence of a beneficial role of Heliox in treatment of severe COPD is lacking and therefore its wide scale use cannot be recommended based on this analysis. Heliox may improve alveolar ventilation and gas transfer but a randomised controlled trial without NIV as a co-intervention is needed to further elucidate its role. Heliox may confer a benefit in reduced odds of intubation. Based on this, in the individual case of severe COPD where intubation is required but would be undesirable, it is a treatment worthy of consideration.

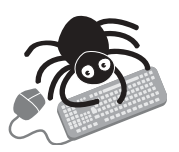

The appendix showing the exclusion log is available on the journal web site (http://www.emjonline.com/ supplemental).

\section{Authors' affiliations}

R Andrews, M Lynch, Emergency Department, Kingston Hospital NHS Trust, London, UK

Funding: none.

Conflicts of interest: none declared. 


\section{REFERENCES}

1 Papamoschou D. Theoretical validation of the respiratory benefits of heliumoxygen mixtures. Respir Physiol 1995;99:183-90.

2 Polito A, Fessler $\mathrm{H}$. Heliox in respiratory failure from obstructive lung disease. N Engl J Med 1995;332:192.

3 Gerbeaux $P$, Boussuges $A$, Torro $D$, et al. Heliox in the treatment of obstructive hypoventilation. Am J Emerg Med 1998;16:215-16.

4 Austan F, Polise M. Management of respiratory failure with noninvasive positive pressure ventilation and Heliox adjunct. Heart Lung 2002;31:214-18.

5 Rodrigo G, Pollack C, Rodrigo C, et al. Heliox for treatment of exacerbations of chronic obstructive pulmonary disease. Cochrane Library. Issue 3. Oxford: Update Software, 2002.

6 Chalmers TC, Smith H, Blackburn B, et al. A method for assessing the quality of a randomised controlled trial. Control Clin Trials 1981;2:31-49.

7 Jadad AR, Moore RA, Carrol D, et al. Assessing the quality of reports of randomized clinical trials: is blinding necessary? Control Clin Trials 1996;17:1-12.

8 Egger M, Dickersin K, Davey Smith G. Systematic reviews in healthcare. London: BMJ Books, 2001.

9 Schulz KF, Chalmers I, Hayes RJ, et al. Empirical evidence of bias. Dimensions of methodological quality associated with estimates of treatment effects in controlled trials. JAMA 1995;273:408-12.
10 Jaber S, Fodil R Carlucci A et al. Noninvasive ventilation with helium-oxygen in acute exacerbations of chronic obstructive pulmonary disease. Am J Respir Crit Care Med 2000;161:1191-200.

11 Nyarko-Adomfeh C, Kiyici N, Rincon H. Helium-oxygen mixtures in adult patients and CO2 retention. Chest 1995;108:157s.

12 Harrison P, Onorato D. The clinical effects of helium-oxygen mixtures on gas exchange in exacerbations of COPD. Chest 1995; 108:156s.

13 Gerbeaux P, Gainnier M, Boussuges A, et al. Use of Heliox in patients with severe exacerbation of chronic obstructive pulmonary disease. Crit Care Med $2001 ; 29: 2322-4$

14 Albornoz G, Xiang Fu H, Doherty J, et al. Heliox reduces the incidence of mechanical ventilation in asthma and chronic obstructive airways disease. Crit Care Med 1998;26:A110.

15 Swidwa D, Montenegro H, Goldman $M$, et al. Helium-oxygen breathing in severe chronic obstructive airways disease. Chest 1985;87:790-6.

16 Jolliet $\mathbf{P}$, Tasseaux D, Thouret J, et al. Beneficial effects of helium:oxygen versus air:oxygen noninvasive pressure support in patients with decompensated chronic obstructive airways disease. Crit Care Med 1999;27:2422-9

17 Thiriet $\mathrm{M}$, Douguet $\mathrm{D}$, Bonnet JC, et al. The effect on gas mixing of a He-O2 mixture in chronic obstructive lung diseases. Bull Physiopathol Respir (Nancy) 1979:15:1053-68. 